\title{
Functional status and its associated factors among community-dwelling older adults in rural Nepal: findings from a cross-sectional study
}

Saruna Ghimire ${ }^{1 \dagger}$, Grish Paudel ${ }^{2 \dagger}$, Sabuj Kanti Mistry ${ }^{3,4}$, Mahmood Parvez $^{3}$, Binod Rayamajhee ${ }^{5}$, Pravash Paudel ${ }^{6}$, Man Kumar Tamang ${ }^{7}$ and Uday Narayan Yadav $2,4,6,8^{*}$

\begin{abstract}
Background: The high burden of chronic conditions, coupled with various physical, mental, and psychosocial changes that accompany the phenomenon of aging, may limit the functional ability of older adults. This study aims to assess the prevalence of poor functional status and investigate factors associated with poor functional status among community-dwelling older adults in rural communities of eastern Nepal.

Methods: Data on 794 older adults aged $\geq 60$ years from a previous community-based cross-sectional study was used. Participants were recruited from rural municipalities of Morang and Sunsari districts of eastern Nepal using multi-stage cluster sampling. Functional status was assessed in terms of participants' ability to perform activities of daily living using the Barthel Index. Covariates included sociodemographic characteristics, lifestyle factors, and selfreported chronic conditions. A binary logistic regression model was used to investigate factors associated with poor functional status.

Results: The overall prevalence of poor functional status was $8.3 \%$ (male: $7.0 \%$ and female: $9.6 \%$ ), with most dependence noted for using stairs (17.3\%), followed by dressing (21.9\%) on Barthel Index. In the adjusted model, oldest age group (odds ratio $[\mathrm{OR}]=2.83,95 \% \mathrm{Cl}: 1.46,5.50$ ), those unemployed $(\mathrm{OR}=2.41,95 \% \mathrm{Cl}: 1.26,4.65$ ), having memory/concentration problems ( $\mathrm{OR}=2.32,95 \% \mathrm{Cl}: 1.30,4.13)$, depressive symptoms $(\mathrm{OR}=2.52,95 \% \mathrm{Cl}$ : $1.28,4.95)$, and hypertension $(\mathrm{OR}=1.78,95 \% \mathrm{Cl}: 1.03,3.06)$ had almost or more than two times poor functioning.

Conclusions: One in 12 older adults had poor functional status as indicated by their dependency on the items of the Barthel Index; those in the oldest age bracket were more likely to exhibit poor functional status. We suggest future studies from other geographies of the country to supplement our study from the rural setting for comprehensive identification of the problem, which could guide the development of prevention strategies and comprehensive interventions for addressing the unmet needs of the older adults for improving functional status.
\end{abstract}

Keywords: Barthel Index, Activities of daily living, Functional Status, Oder adults, Nepal

\footnotetext{
* Correspondence: unyadav1@gmail.com

${ }^{2}$ Centre for Research Policy and Implementation, Biratnagar, Nepal

${ }^{4}$ Centre for Primary Health Care and Equity, University of New South Wales, Sydney, Australia

Full list of author information is available at the end of the article
}

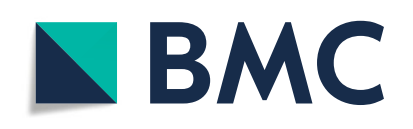

(- The Author(s). 2021 Open Access This article is licensed under a Creative Commons Attribution 4.0 International License, which permits use, sharing, adaptation, distribution and reproduction in any medium or format, as long as you give appropriate credit to the original author(s) and the source, provide a link to the Creative Commons licence, and indicate if changes were made. The images or other third party material in this article are included in the article's Creative Commons licence, unless indicated otherwise in a credit line to the material. If material is not included in the article's Creative Commons licence and your intended use is not permitted by statutory regulation or exceeds the permitted use, you will need to obtain permission directly from the copyright holder. To view a copy of this licence, visit http://creativecommons.org/licenses/by/4.0/. The Creative Commons Public Domain Dedication waiver (http://creativecommons.org/publicdomain/zero/1.0/) applies to the data made available in this article, unless otherwise stated in a credit line to the data. 


\section{Background}

In Nepal, a South Asian country between India and China, the legal provision identifies citizens aged 60 and above as "Senior Citizens" [1]. Nepali older adults' population is burgeoning; from $3.8 \%$ of the total population in 1950 to $8.6 \%$ in 2019 , and is projected to be $10.7 \%$ by 2030 [2]. The population growth rate for older adults $(3.5 \%)$ is greater than the overall population growth rate (2\%) of the country [3]. The demographic transition is happening concurrently with the epidemiological transition, resulting in an increased burden of chronic diseases.

The prevalence of chronic health conditions is higher in older age groups [4], in general and also among Nepali older adults [5]. The high burden of prevalent conditions coupled with the various physical, mental, and psychosocial changes that accompany the phenomenon of aging [6], may limit the functional ability of older adults, and consequently, they may need assistance to perform daily activities such as eating, cooking, bathing, moving around, shopping, and managing finances and medications, etc. [7]. These routine activities are used as an indicator of a person's functional status and are categorized into activities of daily living (ADL) and instrumental activities of daily living (IADL). ADL includes activities related to one's basic physical needs, such as personal hygiene or grooming, dressing, toileting, transferring or ambulating, and eating, while IADL includes more complex activities of independent living such as managing finances and medications, food preparation, housekeeping, laundry, etc. Notably, disability (dependency on others for basic activities) is commonly defined in terms of difficulty performing ADL and IADL [8]. Globally, over $45 \%$ of older adults aged 60 and over have difficulty performing everyday activities, and over 250 million people experience moderate and severe disabilities $[9,10]$. The inability to perform essential everyday activities is also positively correlated with poor quality of life, increased hospitalization [11, 12], increased mistreatment [13], and the need for more physical and social support [14-16]. Inclusion and participation of older adults, with and without disabilities, in the society is in line with the 2030 Agenda for Sustainable Development as well as that of an agefriendly world [10]. Despite this, the prevalence of disability among older people shows an increasing trend $[17,18]$ and may jeopardize older adults' full participation in the society.

In Nepal, more than three-fourth of the older adults live in an extended family and receive informal care from family members [2]. Long-term institutional care is almost non-existent in Nepal, and only a handful of facilities are available in urban Nepal. Nevertheless, advocacy for long-term care is rising, especially due to changing family structure and high migration of adult children [19]. Such dynamics are likely to impact older adults' caregiving seriously, and specifically, those with disabilities are more likely to be affected. Given that the demographic transitions are recent in Nepal, our knowledge of different aspects of aging in Nepal is limited. There is a lack of nationally representative studies on the health and wellbeing of older adults in general, and more specifically, as it relates to disability. Since Nepal is in the early stage of developing policies to address the older population's health, social and financial needs, understanding their ADL/IADL disability or poor functioning is important for prioritizing areas for policy action. Orienting intrinsic capacity and functional ability-based health system is one of the strategic objectives of Global Strategy and Action Plan on Ageing and Health, 2016 [20]. However, to date, only one study from urban Nepal quantified ADL among Nepali older adults and reported that $8 \%$ of the participants had difficulty with at least one ADL on the Katz scale [21]. Given that more than $80 \%$ of the older adults live in rural Nepal, the previous study [21] is less likely to provide a comprehensive picture.

Our study, conducted among rural older residents, will supplement the previous study and help us to better understand the functional status of Nepali older adults. Various lifestyle-related factors such as age, gender, ethnicity, marital status, educational attainment, occupation, income, alcohol consumption, smoking, different chronic diseases, physical inactivity, depression etc. influence disability among older people [22-26]. Notably, most of these factors could be managed with appropriate clinical and public health intervention. Hence, knowledge of the factors associated with poor functional status may help local stakeholders to identify risk groups and risk factors for targeted interventions. Additionally, to date, there has been no evidence from the southern plain of Nepal, where most of the marginalized communities (Madhesi, Dalits, and Indigenous groups) reside. With this multifold relevance noted, this study aims to investigate the prevalence of poor functional status and its associated factors among community-dwelling older people in rural eastern Nepal.

\section{Methodology}

\section{Study design and study participants}

This study used data on 794 older adults from a previous community-based cross-sectional study conducted in the rural municipalities of two districts of eastern Nepal- Morang and Sunsari. According to the most recent census, which dates back to 2011 [3], with a total of 213,997 households in 1,855 Sq. Km., Morang district had a total population of 965,370 , of which $8.2 \%$ were 60 and older. Similarly, in Sunsari districts, there were a 
total of 162,407 households in a total area of 1,257 sq. $\mathrm{Km}$. and included a total population of 763,487 , of which $7.5 \%$ of the population was $60+$. Details of the study design are available somewhere else [14, 27]. Briefly, data were collected between January and April in 2018 using a multi-stage cluster sampling technique. First, four rural municipalities from each district were randomly selected, followed by a random selection of five wards in each municipality. From the list of eligible subjects in each municipality, study participants were randomly selected. Inclusion criteria included Nepali nationals age $\geq 60$ years and residents of the study area for at least a year. Data were collected by semi-structured face-to-face interviews in Nepali.

\section{Study variables}

\section{Dependent variable}

Functional status, the outcome variable, is defined in terms of ADL, measured using Barthel Index [28] that assess participants' independence or dependence on ten everyday activities such as feeding, bathing, dressing, grooming, bowel and bladder control, toilet use, transfers, mobility, and stairs use (Supplemental Table 1). Notably, the index indicates what a patient does and not what a patient could do. The cumulative score for Barthel Index ranges from 0 to 100; a score of $>60$ was considered as good functional status (that indicates greater ability to perform everyday tasks without assistance), and $\leq 60$ indicates the poor functional status (or greater dependence to perform everyday tasks). The Cronbach alpha for the Barthel Index in the current study was 0.82 .

\section{Independent variables}

For this study, we used the biopsychosocial model of disability, supported by the International Classification of Functioning, Disability, and Health, which integrates both medical and social models of disability. Accordingly, disability and functioning are viewed as outcomes of interactions between health conditions and contextual factors [29]. Consequently, we included sociodemographic characteristics (participants' age, sex, ethnicity, marital status, educational status, past occupation, and monthly family income in Nepali rupee), lifestyle factors (history of smoking and alcohol use, and physical activity), and health status (depressive symptoms, memory or concentration problem and different chronic conditions) as the explanatory variables. Educational status, assessed in terms of the number of formal schooling, was categorized into with and without any formal schooling/education. History of smoking and alcohol use was assessed as dichotomous (yes/no) responses. Participants were considered to be physically inactive if they reported not engaging in different types of moderate-to-vigorous activities (i.e., walking, jogging, yoga, cycling, exercise, swimming, weightlifting, activities related to the farmhouse, etc.) in the past week; otherwise, they were classified as physically active. Depressive symptoms were assessed using the 15-item Geriatric Depression Scale, details of which are published elsewhere [5]. These independent variables are also described in our previously published paper [30]. Five self-reported chronic conditions, i.e., hypertension, arthritis, cardiovascular diseases, diabetes, and chronic obstructive pulmonary diseases, were assessed by asking participants if a health professional ever told them that they had the condition.

\section{Statistical analyses}

Frequency (\%) distribution of independent variables by functional status is reported, and group differences in frequencies were tested using the Chi-square test. We used binary logistic regression models to explore the factors associated with participants' poor functional status, where the final model was selected using the backward elimination criteria with the Akaike information criterion (AIC) approach. We used variance inflation factors (VIF) for assessing the multicollinearity of variables. Adjusted odds ratio (OR) and $95 \%$ confidence intervals ( $95 \% \mathrm{CI})$ of the variables in the final model are reported. All analyses were performed using the Stata software (Version 14.0).

\section{Results}

Sociodemographic and lifestyle characteristics and health profile of the participants

The mean age of participants was 69.9 years (male: $70.2 \pm 8.5$; female: $69.7 \pm 8.9$ ), and the majority were in their sixties (Table 1). Roughly equal representation of males and females was noted. Participants from Aadiwasi/Janjatis and Madeshi ethnic group represented over $70 \%$ of the participants. The majority of the participants were married (53.5\%), without formal education $(80.1 \%)$, unemployed in the past $(54.2 \%)$, had a history of smoking (62.2\%), and were physically inactive (77.1\%) (Table 1). About $56 \%$ reported depressive symptoms, and various chronic conditions were prevalent (Table 1).

\section{Functional status}

The overall prevalence of poor functional status was $8.3 \%$ (male: $7.0 \%$ and female: $9.6 \%$ ) (Table 1). Supplemental Table 1 reports participants' responses to each item on the Barthel index of functional status. Participants reported most inability to dress (21.9\%), followed by using stairs (17.2\%), mobility (6.6\%), bathing $(6.8 \%)$, grooming (5.6\%), and using the toilet $(3.6 \%)$ while other activities were $<2 \%$ prevalent (Supplemental Table 1). 
Table 1 Sociodemographic and lifestyle characteristics by functional status ( $N=794$ )

\begin{tabular}{|c|c|c|c|c|}
\hline \multirow[t]{2}{*}{ Characteristics } & \multirow{2}{*}{$\begin{array}{l}\text { Total } \\
\text { (\%) }\end{array}$} & \multicolumn{3}{|l|}{ Functional status (\%) } \\
\hline & & Good $(n=728,91.6 \%)$ & Poor $(n=66,8.3 \%)$ & $P$-value \\
\hline \multicolumn{5}{|l|}{ Age (year) } \\
\hline $60-69$ & $440(55.4)$ & $416(94.6)$ & $24(5.4)$ & $<0.001$ \\
\hline $70-79$ & $235(29.6)$ & $215(91.5)$ & $20(8.5)$ & \\
\hline$\geq 80$ & $119(15.0)$ & $97(81.5)$ & $22(18.5)$ & \\
\hline \multicolumn{5}{|l|}{ Gender } \\
\hline Male & $400(50.4)$ & $372(93.0)$ & $28(7.0)$ & 0.177 \\
\hline Female & $394(49.6)$ & $356(90.4)$ & $38(9.6)$ & \\
\hline \multicolumn{5}{|l|}{ Ethnicity } \\
\hline Aadiwasi/Janjatis & $298(37.5)$ & $276(92.6)$ & $22(7.4)$ & 0.672 \\
\hline Brahmin/Chettri/Thakur & $69(8.7)$ & $65(94.2)$ & $4(5.8)$ & \\
\hline Dalit & $157(19.8)$ & $142(90.5)$ & $15(9.6)$ & \\
\hline Madeshi and others & $270(34.0)$ & $245(90.7)$ & $25(9.3)$ & \\
\hline \multicolumn{5}{|l|}{ Marital status } \\
\hline Married & $425(53.5)$ & $400(94.1)$ & $25(5.9)$ & 0.008 \\
\hline Without partner ${ }^{a}$ & $369(46.5)$ & $328(88.9)$ & $41(11.1)$ & \\
\hline \multicolumn{5}{|l|}{ Educational status } \\
\hline Without formal education & $636(80.1)$ & $583(91.7)$ & $53(8.3)$ & 0.966 \\
\hline With formal education & $158(19.9)$ & $145(91.8)$ & $13(8.2)$ & \\
\hline \multicolumn{5}{|l|}{ Past occupation } \\
\hline Employed & $364(45.8)$ & $351(96.4)$ & $13(3.6)$ & $<0.001$ \\
\hline Unemployed & $430(54.2)$ & $377(87.7)$ & $53(12.3)$ & \\
\hline \multicolumn{5}{|l|}{ Family monthly income ${ }^{b}$} \\
\hline $\mathrm{NRP} \leq 5,000$ & $381(48.0)$ & $348(91.3)$ & $33(8.7)$ & 0.921 \\
\hline NRP $5,000-\leq 10,000$ & $145(18.3)$ & $134(92.4)$ & $11(7.6)$ & \\
\hline $\mathrm{NRP}>10,000$ & $268(33.8)$ & $246(91.8)$ & $22(8.2)$ & \\
\hline \multicolumn{5}{|l|}{ History of smoking } \\
\hline No & $300(37.8)$ & $281(93.7)$ & $19(6.3)$ & 0.115 \\
\hline Yes & $494(62.2)$ & $447(90.5)$ & $47(9.5)$ & \\
\hline \multicolumn{5}{|l|}{ History of alcohol drinking } \\
\hline No & $504(63.5)$ & $458(90.9)$ & $46(9.1)$ & 0.273 \\
\hline Yes & $290(36.5)$ & $270(93.1)$ & $20(6.9)$ & \\
\hline \multicolumn{5}{|l|}{ Physical activity } \\
\hline Inactive & $612(77.1)$ & $557(91.0)$ & $55(9.0)$ & 0.207 \\
\hline Active & $182(22.9)$ & $171(94.0)$ & $11(6.0)$ & \\
\hline \multicolumn{5}{|l|}{ Memory or concentration problem } \\
\hline No & $486(61.2)$ & $465(95.7)$ & $21(4.3)$ & $<0.001$ \\
\hline Yes & $308(38.8)$ & $263(85.4)$ & $45(14.6)$ & \\
\hline \multicolumn{5}{|l|}{ Depressive symptoms } \\
\hline No & $351(44.2)$ & $339(96.6)$ & $12(3.4)$ & $<0.001$ \\
\hline Yes & $443(55.8)$ & $389(87.8)$ & $54(12.2)$ & \\
\hline \multicolumn{5}{|l|}{ Hypertension } \\
\hline No & $541(68.1)$ & $507(93.7)$ & $34(6.3)$ & 0.002 \\
\hline Yes & $253(31.9)$ & $221(87.4)$ & $32(12.7)$ & \\
\hline
\end{tabular}


Table 1 Sociodemographic and lifestyle characteristics by functional status ( $N=794)$ (Continued)

\begin{tabular}{|c|c|c|c|c|}
\hline \multirow[t]{2}{*}{ Characteristics } & \multirow{2}{*}{$\begin{array}{l}\text { Total } \\
\text { (\%) }\end{array}$} & \multicolumn{3}{|l|}{ Functional status (\%) } \\
\hline & & Good $(n=728,91.6 \%)$ & Poor $(n=66,8.3 \%)$ & $P$-value \\
\hline \multicolumn{5}{|l|}{ Arthritis } \\
\hline No & $463(58.3)$ & $435(94.0)$ & $28(6.1)$ & 0.006 \\
\hline Ye & $331(41.7)$ & $293(88.5)$ & $38(11.5)$ & \\
\hline \multicolumn{5}{|c|}{ Cardiovascular disease } \\
\hline No & $775(97.6)$ & $711(91.7)$ & $64(8.3)$ & 0.723 \\
\hline Ye & $19(2.4)$ & $17(89.5)$ & $2(10.5)$ & \\
\hline \multicolumn{5}{|l|}{ Diabetes } \\
\hline No & $752(94.7)$ & $689(91.6)$ & $63(8.4)$ & 0.778 \\
\hline Ye & $42(5.3)$ & $39(92.9)$ & $3(7.1)$ & \\
\hline \multicolumn{5}{|c|}{ Chronic obstructive pulmonary disease } \\
\hline No & $672(84.6)$ & $623(92.7)$ & $49(7.3)$ & 0.014 \\
\hline Ye & $122(15.4)$ & $105(86.1)$ & $17(13.9)$ & \\
\hline
\end{tabular}

${ }^{a}$ Widowed/divorced/separated/unmarried. ${ }^{\text {b NRP: Nepali rupee; } 1 \text { NRP } ~ 100 ~ U S ~ d o l l a r . ~ S i g n i f i c a n t ~ p-v a l u e s ~ a r e ~ b o l d e d ~}$

Independent variables associated with poor functional status

The full model included participants' sociodemographic and lifestyle characteristics (all variables presented in Table 1). The final model, based on the backward selection using the lowest AIC, is presented in Table 2. Hence, the model is adjusted for all the variables in Table 2. The VIF of the variables included in the model was less than 3.0. In the final model, age, past occupation, memory/concentration problem, depressive symptoms, and hypertension were significantly associated with poor functional status (Table 2). The oldest age

Table 2 Association of sociodemographic, lifestyle, and health status with poor functional status

\begin{tabular}{clll}
\hline Characteristics & Adjusted odds ratio & $\mathbf{9 5 \% ~ C l}$ & $P$ \\
\hline Age (year) & & & \\
$60-69$ & Ref & & \\
$70-79$ & 1.45 & $0.77,2.76$ & 0.250 \\
$\geq 80$ & $\mathbf{2 . 8 3}$ & $\mathbf{1 . 4 6 , 5 . 5 0}$ & $\mathbf{0 . 0 0 2}$ \\
Past occupation & & & \\
Employed & Ref & & \\
Unemployed & $\mathbf{2 . 4 1}$ & $\mathbf{1 . 2 6 , 4 . 6 5}$ & $\mathbf{0 . 0 0 8}$ \\
Memory/concentration problem & & \\
No & Ref & & \\
Yes & $\mathbf{2 . 3 2}$ & $\mathbf{1 . 3 0 , 4 . 1 3}$ & $\mathbf{0 . 0 0 4}$ \\
Depressive symptoms & & & \\
No & Ref & & \\
Yes & $\mathbf{2 . 5 2}$ & $\mathbf{1 . 2 8 , 4 . 9 5}$ & $\mathbf{0 . 0 0 8}$ \\
Hypertension & & & $\mathbf{0 . 0 3 8}$ \\
No & Ref & & \\
Yes & $\mathbf{1 . 7 8}$ & $\mathbf{1 . 0 3 , 3 . 0 6}$ & \\
\hline
\end{tabular}

group ( $\geq 80$ years) had almost three times higher odds of poor functioning $(\mathrm{OR}=2.83,95 \% \mathrm{CI}$ : 1.46, 5.50) compared to the youngest age group (60-69 years). Poor functional status was close to or greater than two times among those unemployed $(\mathrm{OR}=2.41,95 \% \mathrm{CI}$ : 1.26 , $4.65)$, had memory/concentration problems $(\mathrm{OR}=2.32$, $95 \% \mathrm{CI}: 1.30,4.13)$, depressive symptoms $(\mathrm{OR}=2.52$, $95 \% \mathrm{CI}: 1.28,4.95)$, and hypertension $(\mathrm{OR}=1.78$, 95 \% CI: 1.03, 3.06).

\section{Discussion}

With an aim to assess the prevalence and correlates of functional status among older adults in rural Nepal, the present study found that one in 12 older adults had poor functional status. Older age, being unemployed, memory/concentration problems, depressive symptoms, and hypertension were associated with poor functional status.

The estimated $8.3 \%$ prevalence of functional dependency in our study is similar to a previous study from urban Nepal [31]. Biological senescence that results in various physical, mental, and psychosocial changes [6] coupled with prevalent chronic conditions may limit the functional ability of older adults to perform everyday tasks. In general, physical functioning diminish with age, and the speed of deterioration accelerates among older adults [32, 33]. Relatedly, we also noted that compared to our youngest participants (60-69 years), those in the oldest age group ( $\geq 80$ years) had an increased likelihood of poor functioning. The positive association of ADL dependency with age was also observed in previous studies conducted in various settings [34-37], and specifically, individuals above 70 years face problems with multiple ADL items [35, 38]. 
Unemployment, which may serve as a proxy for individuals' low economic status, was associated with more than doubled odds of poor functioning (or increased ADL dependency). Although we did not find any studies that demonstrated the association between past occupational history and ADL performance among older adults, there is a plausibility that older adults with no past employment are very likely to have poor socioeconomic status, which may increase their unmet needs for social, psychological, and physical wellbeing [39]. In line with the common notion that people with lower socioeconomic status have worse health outcomes and a higher risk of premature mortality [40], the cumulative disadvantage theory posits that socioeconomic disadvantages accumulate during the life course to produce differential health outcomes in later life [41]. From these perspectives, past employment may protect against the decline of physical functioning because of cumulative advantages over the life course. Relatedly, previous studies indicate that older adults with past employment history have a better socioeconomic status for fulfilling daily needs and tend to have a positive attitude towards physical activities, which makes older adults performed better on ADL [42, 43]. Likewise, a longitudinal study conducted among Japanese older adults 70 years and older also indicated that engagement in work might contribute to independence in terms of ADL [44].

The noted increased odds of poor functioning among those reporting depressive symptoms are also supported by previous studies that indicate depressive symptoms impair functional capacity to perform services such as shopping, preparing meals, moving within the community, and taking medications on time $[45,46]$. Potential mechanisms underlying the relationship between depressive symptoms and development of functional disability includes enhanced decline of physical functioning over time due to prolonged presence of certain somatic depressive symptoms [47], amplified symptom burden and complications of chronic medical conditions [48], negative health behaviors (such as physical inactivity, obesity, and smoking [49], and non-compliance to various treatment regimens [49]; all of which facilitate the onset of functional disability among the older population.

In line with previous studies that concluded that memory or attention deficiencies are significant predictors of ADL dependency among older adults [50,51], our participants with memory or concentration problem were at higher odds of poor functioning. Severe memory deficits is one of the earliest and most pronounced symptoms of cognitive impairment related to Alzheimer's disease, which often causes ADL limitations in older adults [52]. An earlier study also suggested that attentional impairments may be driving impairment in ADL among older people [53].
Hypertension was identified as a risk factor for poor functioning among our study participants which is supported by a number of previous studies $[54,55]$ that reported greater limitations in ADL among hypertensive older adults. Additionally, evidence suggests that antihypertensive medications can prevent or delay subsequent ADL limitations in older adults [56]. However, there remains controversy regarding the optimal treatment of hypertension in the older population, especially the oldest age group [57]. Therefore, other methods of hypertension control (e.g., lifestyle change) can be prioritized to reduce the higher ADL dependence among the older population.

\section{Strength and limitations of the study}

This study has its own strength and limitations. Strengths of this study include a first study to assess the functional status or ADL dependency among older adults in rural eastern Nepal with a high response rate ( $>95 \%$ ) and the use of trained enumerators for data collection in the community setting. This study is subjected to certain limitations that included: (a) associations were derived from a cross-sectional study, therefore precludes cause-effect relationship and (b) generalizability of findings is limited to rural settings of Morang and Sunsari district. Additionally, data obtained in this study were self-reported, which may be subjected to social desirability and recall bias. The possibility of reverse causality is also possible given that the relationship between functional status and health conditions could be bidirectional.

\section{Conclusions}

In summary, our study found that one in 12 older adults has poor functional status in rural Nepal, with those in the oldest age bracket more likely to exhibit poor functioning. The study finding highlights the necessity to give special attention to relatively older Nepalese adults, who are at higher risk for poor functioning or ADL dependence. Therefore, evidence-based programs for older adults to improve ADL independence and environments for maintaining independence are warranted [58]. Hypertension and depressive symptoms, both amenable to psychosocial interventions [59], were associated with increased odds of dependency. Therefore, culturally tailored interventions aimed at screening and subsequently treating depression and lifestyle changes for hypertension need to be developed to address these conditions and subsequent functional disability in this population. We suggest future studies from other geographies of the country to supplement our study from the rural for comprehensive identification of the problem, which could guide the development of prevention strategies and comprehensive interventions for addressing the 
unmet needs of the older adults for improving physical functioning.

\section{Abbreviations}

ADL: Activities of daily living.: OR: Odds ratio.; Cl: Confidence nterval.; IADL: Instrumental activities of daily living.; VIF: Variance inflation factors.

\section{Supplementary Information}

The online version contains supplementary material available at https://doi. org/10.1186/s12877-021-02286-8

Additional file 1: Supplemental Table 1. Participants response to 10 items on Barthel Index (BI) of activities of daily living.

\section{Acknowledgements}

We would like to thank all the participants of this study and local government bodies.

\section{Authors' contributions}

Conceived and designed the experiments: UNY and MKT. Performed fieldwork: UNY and MKT. Analysed the data: UNY, SG and SKM. Wrote the paper: SG, GP, SKM, MP, BRM, PP, MKT and UNY. All authors read and approved the final manuscript.

\section{Funding}

UNY received funding from Nepal Health Research Council, Ministry of Health and Population, Government of Nepal (Provincial grant). The funders had no role in the study design, data collection, and analysis of the data.

\section{Availability of data and materials}

The datasets used and/or analyzed during the current study are available from the corresponding author on reasonable request.

\section{Declarations}

\section{Ethics approval and consent to participate}

Research was performed in accordance with the Declaration of Helsinki and was approved by the ethics committee at Nepal Health Research Council, Ministry of Health and Population. Informed consent was obtained from all study participants.

\section{Consent for publication}

Not applicable.

\section{Competing interests}

The authors declare that they have no competing interests.

\section{Author details}

${ }^{1}$ Department of Sociology and Gerontology and Scripps Gerontology Center, Miami University, 45056 Oxford, OH, USA. ${ }^{2}$ Centre for Research Policy and Implementation, Biratnagar, Nepal. ${ }^{3}$ James P Grant School of Public Health, BRAC University, Dhaka, Bangladesh. ${ }^{4}$ Centre for Primary Health Care and Equity, University of New South Wales, Sydney, Australia. ${ }^{5}$ School of Optometry, University of New South Wales, Sydney, Australia. ${ }^{6}$ School of Population Health, University of New South Wales, Sydney, Australia. ${ }^{7}$ Queensland Brain Institute, The University of Queensland, Brisbane, Australia ${ }^{8}$ Torrens University, Sydney, Australia.

\section{Received: 6 January 2021 Accepted: 10 May 2021}

Published online: 25 May 2021

\section{References}

1. Nepal Law Commission. Senior Citizens Act. 2063 (2006). Kathmandu, Nepal. Available at: https://www.ilo.org/dyn/natlex/docs/ELECTRONIC/87505/99802/ F775759502/NPL87505.pdf.

2. United Nations Department of Economic and Social Affairs. Profiles of Ageing: United Nations 2019 [Available from: https://population.un.org/ ProfilesOfAgeing2019/index.html. Accessed 11 Mar 2019.
3. Central Bureau of Statistics. National Population and Housing Census 2011 (National Report). Kathmandu, Nepal: Government of Nepal National Planning Commission Secretariat; 2012.

4. Amin S, Bajracharya, A., Bongaarts, J., Chau, M., Melnikas, A.J. Demographic Changes of Nepal: Trends and Policy Implications; Kathmandu: Nepal Planning Commission, Government of Nepal.; 2017.

5. Yadav UN, Thapa TB, Mistry SK, Pokhrel R, Harris MF. Socio-demographic characteristics, lifestyle factors, multi-morbid conditions and depressive symptoms among Nepalese older adults. BMC Psychiatry. 2020;20(1):261. https://doi.org/10.1186/s12888-020-02680-3.

6. World Health Organization. World report on ageing and health. Geneva; 2015. Available at: http://apps.who.int/iris/bitstream/handle/10665/186463/ 9789240694811_eng.pdf?sequence=1.

7. Illario M, Vollenbroek-Hutten MM, Molloy DW, Menditto E, laccarino G, Eklund P. Active and Healthy Ageing and Independent Living 2016. J Aging Res. 2016;2016:8062079.

8. Tas U, Verhagen AP, Bierma-Zeinstra SM, Odding E, Koes BW. Prognostic factors of disability in older people: a systematic review. Br J Gen Pract. 2007:57(537):319-23.

9. United Nations Department of Economic and Social Affairs. Ageing and disability 2015 [Available from: https://www.un.org/development/desa/disa bilities/disability-and-ageing.html. Accessed 11 Mar 2019.

10. World Health Organization. Age Friendly World 2019 [Available from: https://extranet.who.int/agefriendlyworld/. Accessed 11 June 2020.

11. Mudge AM, McRae P, Hubbard RE, Peel NM, Lim WK, Barnett AG, et al. Hospital-Associated Complications of Older People: A Proposed Multicomponent Outcome for Acute Care. J Am Geriatr Soc. 2019;67(2):352-

12. Gurung L, Paudel G, Yadav UN. Health Service Utilization by Elderly Population in Urban Nepal: A Cross-Sectional Study. JMMIHS. 2016;2. Available at: https://bit.ly/3yq9mdV.

13. Yadav UN, Paudel G. Prevalence and associated factors of elder mistreatment: a cross sectional study from urban Nepal. Age and Ageing. 2016:45(5):609-13.

14. Yadav UN, Tamang MK, Thapa TB, Hosseinzadeh H, Harris MF, Yadav KK. Prevalence and determinants of frailty in the absence of disability among older population: a cross sectional study from rural communities in Nepal. BMC Geriatrics. 2019;19(1):283.

15. Katz S. Assessing self-maintenance: activities of daily living, mobility, and instrumental activities of daily living. J Am Geriatr Soc. 1983:31(12):721-7.

16. Thompson WW, Zack MM, Krahn GL, Andresen EM, Barile JP. Health-related quality of life among older adults with and without functional limitations. American journal of public health. 2012;102(3):496-502.

17. Lin SF, Beck AN, Finch BK, Hummer RA, Masters RK. Trends in US older adult disability: exploring age, period, and cohort effects. American journal of public health. 2012;102(11):2157-63.

18. Chatterji S, Byles J, Cutler D, Seeman T, Verdes E. Health, functioning, and disability in older adults-present status and future implications. Lancet. 2015:385(9967):563-75.

19. Parker SL, Pant B. Longevity in Nepal, Environmental, Health and Policy Challenges. Int J Soc Syst Sci. 2011:3(4):333-45.

20. Global strategy and action plan on ageing and health. Geneva: World Health Organization 2017.

21. Chalise HN. Socio-Demographic and Health Status of Nepalese Elderly. Indian Journal of Gerontology. 2012;26:151-60.

22. Stuck AE, Walthert JM, Nikolaus T, Büla CJ, Hohmann C, Beck JC. Risk factors for functional status decline in community-living elderly people: a systematic literature review. Soc Sci Med. 1999;48(4):445-69.

23. Taș U, Verhagen AP, Bierma-Zeinstra SM, Hofman A, Odding E, Pols HA et al. Incidence and risk factors of disability in the elderly: the Rotterdam Study. Prev Med. 2007:44(3):272-8.

24. Connolly D, Garvey J, McKee G. Factors associated with ADL/IADL disability in community dwelling older adults in the Irish longitudinal study on ageing (TILDA). Disability and Rehabilitation. 2017;39(8):809-16.

25. Carmona-Torres JM, Rodríguez-Borrego MA, Laredo-Aguilera JA, López-Soto PJ, Santacruz-Salas E, Cobo-Cuenca Al. Disability for basic and instrumental activities of daily living in older individuals. PLOS ONE. 2019;14(7):e0220157.

26. Ramsay SE, Whincup PH, Morris RW, Lennon LT, Wannamethee SG. Extent of Social Inequalities in Disability in the Elderly: Results From a Populationbased Study of British Men. Annals of Epidemiology. 2008:18(12):896-903. 
27. Yadav UN, Tamang MK, Thapa TB, Hosseinzadeh H, Harris MF, Yadav KK. Prevalence and determinants of frailty in the absence of disability among older population: a cross sectional study from rural communities in Nepal. BMC Geriatr. 2019;19(1):283.

28. Mahoney FI, Barthel DW. Functional evaluation: the barthel index. Md State Med J. 1965;14:61-5.

29. Towards a Common Language for Functioning, Disability and Health. Geneva, Switzerland: World Health Organisation 2002.

30. Yadav UN, Tamang MK, Paudel G, Kafle B, Mehta S, Chandra Sekaran V, et al. The time has come to eliminate the gaps in the under-recognized burden of elder mistreatment: A community-based, cross-sectional study from rural eastern Nepal. PLOS ONE. 2018;13(6):e0198410.

31. Chalise HN, Saito T, Kai I. Functional disability in activities of daily living and instrumental activities of daily living among Nepalese Newar elderly. Public Health. 2008:122(4):394-6.

32. Fiest KM, Jetté N, Roberts Jl, Maxwell CJ, Smith EE, Black SE, et al. The Prevalence and Incidence of Dementia: a Systematic Review and Metaanalysis. Can J Neurol Sci. 2016;43 Suppl 1:S3-s50.

33. van der Vorst A, Zijlstra GAR, Witte ND, Duppen D, Stuck AE, Kempen GIJM, et al. Limitations in Activities of Daily Living in Community-Dwelling People Aged 75 and Over: A Systematic Literature Review of Risk and Protective Factors. PLOS ONE. 2016;11(10):e0165127.

34. Wahrendorf M, Reinhardt JD, Siegrist J. Relationships of disability with age among adults aged 50 to 85: evidence from the United States, England and continental europe. PLoS One. 2013;8(8):e71893. https://doi.org/10.1371/ journal.pone.0071893.

35. Connolly D, Garvey J, McKee G. Factors associated with ADL/IADL disability in community dwelling older adults in the lrish longitudinal study on ageing (TILDA). Disabil Rehabil. 2017;39(8):809-16. https://doi.org/10.3109/ 09638288.2016.1161848

36. Chalise HN, Saito T, Kai I. Functional disability in activities of daily living and instrumental activities of daily living among Nepalese Newar elderly. Publ Health. 2008;122(4):394-6. https://doi.org/10.1016/j.puhe.2007.07.015.

37. Fusco O, Ferrini A, Santoro M, Lo Monaco MR, Gambassi G, Cesari M. Physical function and perceived quality of life in older persons. Aging Clin Exp Res. 2012 Feb;24(1):68-73. https://doi.org/10.1007/BF03325356. PMID: 22643307

38. Ćwirlej-Sozańska AB, Sozański B, Wiśniowska-Szurlej A, WilmowskaPietruszyńska A. An assessment of factors related to disability in ADL and IADL in elderly inhabitants of rural areas of south-eastern Poland. Ann Agric Environ Med. 2018 Sep 25;25(3):504-511. https://doi.org/10.26444/aaem/ 81311. Epub 2018 Mar 5. PMID: 30260182.

39. Abdi S, Spann A, Borilovic J, de Witte L, Hawley M. Understanding the care and support needs of older people: a scoping review and categorisation using the $\mathrm{WHO}$ international classification of functioning, disability and health framework (ICF). BMC Geriatrics. 2019;19(1):195.

40. Winkleby MA, Jatulis DE, Frank E, Fortmann SP. Socioeconomic status and health: how education, income, and occupation contribute to risk factors for cardiovascular disease. American journal of public health. 1992;82(6): 816-20

41. Dannefer D. Cumulative Advantage/Disadvantage and the Life Course: Cross-Fertilizing Age and Social Science Theory. The Journals of Gerontology: Series B. 2003;58(6):S327-S37.

42. Guralnik JM, Kaplan GA. Predictors of healthy aging: prospective evidence from the Alameda County study. American journal of public health. 1989; 79(6):703-8

43. Guralnik JM, Land KC, Blazer D, Fillenbaum GG, Branch LG. Educational status and active life expectancy among older blacks and whites. The New England journal of medicine. 1993;329(2):110-6.

44. Ishizaki T, Kobayashi Y, Kai I. Functional transitions in instrumental activities of daily living among older Japanese. J Epidemiol. 2000;10(4):249-54.

45. Yadav UN, Thapa TB, Mistry SK, Pokhrel R, Harris MF. Socio-demographic characteristics, lifestyle factors, multi-morbid conditions and depressive symptoms among Nepalese older adults. BMC Psychiatry. 2020;20(1):261.

46. Penninx BWJH, Guralnik JM, Ferrucci L, Simonsick EM, Deeg DJH, Wallace RB. Depressive Symptoms and Physical Decline in Community-Dwelling Older Persons. JAMA. 1998;279(21):1720-6.

47. Bruce ML. Depression and disability in late life: directions for future research. Am J Geriatr Psychiatry. 2001 Spring;9(2):102-12.
48. Katon, Wayne J. "Epidemiology and treatment of depression in patients with chronic medical illness." Dial Clin Neurosci. 2011;13(1):7-23. https://doi. org/10.31887/DCNS.2011.13.1/wkaton

49. Penninx BW, Leveille S, Ferrucci L, van Eijk JT, Guralnik JM. Exploring the effect of depression on physical disability: longitudinal evidence from the established populations for epidemiologic studies of the elderly. Am J Public Health. 1999;89(9):1346-52. https://doi.org/10.2105/ajph.89.9.1346.

50. Guilley E, Ghisletta P, Armi F, Berchtold A, d'Epinay CL, Michel J-P, et al. Dynamics of frailty and ADL dependence in a five-year longitudinal study of octogenarians. Res Aging. 2008;30(3):299-317. https://doi.org/10.1177/0164 027507312115.

51. Bronnick K, Ehrt U, Emre M, De Deyn PP, Wesnes K, Tekin S, Aarsland D. Attentional deficits affect activities of daily living in dementia-associated with Parkinson's disease. J Neurol Neurosurg Psychiatry. 2006;77(10):1136-42. https://doi.org/10.1136/jnnp.2006.093146.

52. Tabira T, Hotta M, Murata M, Yoshiura K, Han G, Ishikawa T, Koyama A, Ogawa N, Maruta M, Ikeda Y, Mori T, Yoshida T, Hashimoto M, Ikeda M. AgeRelated Changes in Instrumental and Basic Activities of Daily Living Impairment in Older Adults with Very Mild Alzheimer's Disease. Dement Geriatr Cogn Dis Extra. 2020;10(1):27-37. https://doi.org/10.1159/000506281.

53. Freilich BM, Hyer LA. Relation of the Repeatable Battery for Assessment of Neuropsychological Status to measures of daily functioning in dementia. Psychol Rep. 2007;101(1):119-29. https://doi.org/10.2466/pr0.101.1.119-129.

54. Caskie Gl, Sutton MC, Margrett JA. The relation of hypertension to changes in ADL/IADL limitations of Mexican american older adults. J Gerontol B Psychol Sci Soc Sci. 2010;65B(3):296-305. https://doi.org/10.1093/geronb/ gbq001.

55. Hozawa A, Okamura T, Murakami Y, Kadowaki T, Okuda N, Takashima N, Hayakawa T, Kita Y, Miura K, Nakamura Y, Okayama A, Ueshima H; NIPPON DATA80 Research Group. High blood pressure in middle age is associated with a future decline in activities of daily living. NIPPON DATA80. J Hum Hypertens. 2009;23(8):546-52. https://doi.org/10.1038/jhh.2008.155.

56. Hajjar I, Lackland DT, Cupples LA, Lipsitz LA. Association between concurrent and remote blood pressure and disability in older adults. Hypertension. 2007;50(6):1026-32. https://doi.org/10.1161/HYPERTENSIONA HA.107.097667.

57. Kim Kl, Cho YS, Choi DJ, Kim CH. Optimal treatment of hypertension in the elderly: a Korean perspective. Geriatr Gerontol Int. 2008:8(1):5-11. https://doi. org/10.1111/j.1447-0594.2008.00440.x.

58. Chen SW, Chippendale T. Factors associated with IADL independence: implications for OT practice. Scand J Occup Ther. 2017;24(2):109-15.

59. Ormel J, Rijsdijk FV, Sullivan M, van Sonderen E, Kempen Gl. Temporal and reciprocal relationship between $I A D L / A D L$ disability and depressive symptoms in late life. J Gerontol B Psychol Sci Soc Sci. 2002;57(4):P338-47. https://doi.org/10.1093/geronb/57.4.p338.

\section{Publisher's Note}

Springer Nature remains neutral with regard to jurisdictional claims in published maps and institutional affiliations.
Ready to submit your research? Choose BMC and benefit from:

- fast, convenient online submission

- thorough peer review by experienced researchers in your field

- rapid publication on acceptance

- support for research data, including large and complex data types

- gold Open Access which fosters wider collaboration and increased citations

- maximum visibility for your research: over $100 \mathrm{M}$ website views per year

At $\mathrm{BMC}$, research is always in progress.

Learn more biomedcentral.com/submission 